\title{
Participação dos pais e mães na realização da lição de casa no Quebec e no Brasil
}

\author{
Parents' participation in the house's lesson
hment of the lesson in Quebec and in Brazil \\ accomplishment of the lesson in Quebec and in Brazil

\section{Participation des parents à la réalisation des devoirs au Québec et au Brésil}

Nilce da SILVA

Michel ROUSSEAU

Rollande DESLANDES

RESUMO

Este artigo trata das razoes que levam os pais do Quebec e do Brasil a se envolverem com os deveres de casa dos seus filhos do ensino fundamental. Os autores pretendem verificar o calor preditivo de cada üm dos motivos que fazem com que os pais se envolvam nesta tarefa segundo o modelo parental de Hoover-Dempsey e Sandler (1995, 1997), a saber: da compreensão que eles têm do seu papel como pais, do sentimento de competência que eles têm nesta direção e ainda da sua percepção freñte aos convites dos professores dos seus filhos. As amostras foram compostas por 250 pais do Quebec e 71, do Brasil. Quaisquer que sejam as características das famílias, os pais do Quebec se implicam, sobretudo, se eles compreendèm sta-responsabilidade como pais enquanto que os brasileiros participam principalmente se eles se sentem competentes para tanto. Os resultados são discutidos levando em consideração as particularidades dos contextos estudados.

Palavras-chave: deveres de casa, Brasil, Quebec, envolvimento dos pais.

\section{ABSTRACT}

This article examines the reasons why parents in Quebec and in Brazil become involved in their children's homework from 4th to 6th grade. The authors aim to verify the predictive value of each of the reasons that motivate parents to become involved in function of Hoover-Dempsey and Sandler $(1995$, 1997)'s model of parental involvement, that is, 
their understanding of their parental role, their self-efficacy and their perceptions of invitations to participate on the part of the teachers. The samples consist of 250 Quebec parents and 71 Brazil parents. Whatever family characteristics, Quebec parents are involved especially if they understand that their participation is part of their responsibilities while parents in Brazil participate depending mainly on their self-efficacy. The results are discussed taking into account the peculiarities of the two contexts of the study.

Index terms: homework, Brazil, Quebec, parental involvement.

\section{RESUME}

Cet article porte sur les raisons qui amènent les parents québécois et brésiliens à s'impliquer dans les devoirs et leçons de leurs enfants de la $4^{\mathrm{e}}$ à la $6^{\mathrm{e}}$ année du primaire. Les auteurs visent à vérifie la valeur prédictive de chacun des motifs qui incitent les parents à s'impliquer selon le modèle de la participation parentale de Hoover-Dempsey et Sandler (1995, 1997), à savoir la compréhension qu'ils ont de leur rôle parental, leur sentiment de compétence et leurs perceptions des invitations à participer de la part des enseignants. Les échantillons sont composés de 250 parents québécois et 71 parents brésiliens. Quelles que soient les caractéristiques familiales, les parents québécois s'impliquent surtout s'ils comprennent que leur participation relève de leurs responsabilités parentales alors que les parents brésiliens participent principalement en fonction de leur sentiment de compétence. Les résultats sont discutés en tenant compte des particưlarités des deux contextes de l'étude. ${ }^{1}$

Mots cles: devoirs et leçons, Brésil, Québec, implication des parents.

\section{Introdução}

De acordo com Cooper (2001), Gill e Schlossman (2003) e Xu e Corno (2003), o momento da lição de casa é de tensão, de batalha. Tanto os pais como os filhos se encontram estressados para realização de tal tarefa. Finalmente, há que e destacar que a lição de casa é vista como um ponto de

\footnotetext{
${ }^{1}$ Les auteurs désirent remercier Thierry Nadeau du département des sciences de l'éducation à l'Université du Québec à Trois-Rivières pour son appui dans la mise en forme des tableaux et dans l'interprétation des résultats de l'étude.
} 
intersecção entre as escolas e as famílias (Cf. HOOVER-DEMPSEY, BASSLER ET BUROW, 1995).

No Quebec, o questionamento sobre as lições de casa é inserido como um movimento que faz apelo a uma maior abertura em direção às famílias e à comunidade, como percebemos em diferentes documentos oficiais (MELS, 2002). Ou seja, nesta província canadense, são colocadas as seguintes questões: o que a escola espera do ponto de vista dos pais? Entretanto, a situação não é tão simples e não pode ser encerrado em apenas um programa governamental como é, por exemplo, a ajuda aos deveres (MELS, 2003). Na mesma direção, observamos a existência de um movimento de abertura da escola em relação à participação dos pais (BRASIL, MINISTÉRIO DA EDUCAÇÃO, 2002; FRANCO, 2002; NOGUEIRA, ROMANELLI, ZAGO, 2000; CARVALHO, 2000).

\section{Quadro teórico}

Apesar destas controvérsias, os pais se implicam no âmbito da realização das lições de casa. Entretanto, as relações entre a participação dos pais nas lições de casa são mitigadas. Em efeito, elas são tanto positł̀vas como negativas (PATALL, COOPER \& ROBINSON, 2007). A participação dos pais constitui uma força positiva quando a proporção de deveres completada é examinada (COOPER e outros, 2000; EPSTEIN e VAN VOORHIS, 2001; HOOVER-DEMPSEY e outros, 2001). Esta participação se transforma em uma força negativa quando a implicação dos pais é inapropriada e não corresponde ao nível de desenvolvimento da criança (COOPER e outros, 2000). Ela pode mesmo ser de diferentes formasfornecer um enquadramento psíquico ou psicológico estruturado, supervisionado, encorajante, dando a ajuda diretamente etc (COOPER e outros, 2000; GRONILCK e RYAN, 1989; HOOVER-DEMPSEY e outros, 2001; WALKER, HOOVER-DEMPSEY, WHETEL e GREEN, 2004). Um 
grande número de estudos colocaram em evidência as diferências da participação dos pais nas lições de casa tendo em vista o status sócioeconômico, das famílias menos favorecidas e menos escolarizadas têm a tendência de se implicar menos que as família mais favorecidas e escolarizadas (AMES, DE STEFANO, WATKINS, \& SHELDON, 1995; DESLANDES, 2005; LAREAU, 1987; SHELDON, 2002). No estudo de Deslandes e outros (2008), realizada com 465 pais de alunos do ensino primário no Quebec, mostra que os pais e mães das famílias tradicionais (pai e mãe biológicos em casa) se implicam mais com os deveres de casa do que as famílias não tradicioais (monoparenais e outras). Todavia, nenhuma diferença é notada quanto à escolarizaçãodòs pais. Em relação aos alủnos com dificuldades escolares, estes trabalhos monstram que os mesmos recebem menos atenção dos seus pais (cf. DAUBER e EPSTEIN, 1993). Outros estudos, entretanto, o inverso, ou seja, que os pais têm a tendência de se implicar mais quando seus filhos obtém um resultado mais fraco na escola ou quando o mesmo tem dificuldade para realização das suas lições de casa e apreciam a ajuda dos pais (CLARK, 1993; WALKER, HOOVERDEMPSEY, REED, \& JONES, 2000). Na mesma ordem de ideias, o estudo de Deslandes e outros (2008) não indicam nenhuma diferença signitificativa na implicação dos pais em função do nível de sucesso na escola de seus filhos.

\section{Capital social}

De acordo com Marjoribamks (2005), o capital social de uma criança é composto pela relação estabelecida entre as influências da família e do meio social em que ela está inserida. Nesta perspectiva, o background de uma família é definido a partir das situação econômica familiar, das aspirações dos seus pais, o contexto cultural da onde provém esta família (por exemplo, a etnia do pai e ou da mãe). O referido autor destaca também 
o estilo de atuação dos pais e ainda as práticas familiares as quais estão habituados, assim como, e ainda as fontes culturais as quais estas crianças podem recorrer quando necessário. Deste modo, para Marjoribanks (2005), a combinação entre capital social e cultural da família pode ser definido como o capital educacional da família. Desta forma, famílias que possuem um capital educacional mais forte colaboram para que a criança tenha melhor acesso ao capital educacional oferecido pela escola e por outras instituições sociais.

No âmbito deste estudo sobre as lições de casa, o capital social é o centro da nossa atenção sob a perspectiva dos adultos que contribuem para a realização das lições de casa junto às suas crianças, considerando estes adultos como um "algo a mais" a ser considerado.

Participação dos pais na realização das lições de casa

As relações entre a participação dos pais na realização das liçỗes de casa e nos resultados escolares são mitigados. Em efeito, eles podem ser tanto negativos como positivos. (PATALL, COOPER, \& ROBINSON, 2007). A participação constitui uma força postiviva quando la proporção de deveres completados é examinada (COOPER ET AL., 2000; EPSTÉN \& VAN VOORHIS, 2001; HOOVER-DEMPSEY et al., 2001). Já, se_constitui como uma força negativa quando a implicação dos pais é inapropriada em termos de dificultar o desenvolvimento da criança (COOPER et al., 2000). Esta pode ter diferentes formas tal como oferecer uma sustentação física ou psicológica estruturada; supervisionar, encorajar, oferecer recompensas, ajudar diretamente, etc (COOPER ET AL., 2000; GROLNICK \& RYAN, 1989; HOOVER-DEMPSEY et al, 2001; WALKER, HOOVERDEMPSEY, WHETSEL, \& GREEN, 2004). Um grande número de estudos colocaram em evidência no que diz respeito à participação dos pais em casa em função do tatus sécio-econômico da família e assim notou-se que as famílias menos favorecidas e menos escolarizadas têm a tendência a se implicar menos do que as mais favorecidas e escolarizadas (AMES, DE 
STEFANO, WATKINS, \& SHELDON, 1995; DESLANDES, 2005; LAREAU, 1987; SHELDON, 2002). Em relação aos alunos com maior dificuldades escolar, certos trabalhos mostraram que os alunso com menor performance recebem menos ajuda dos seus pais (Cf. DAUBER \& EPSTEIN, 1993). Outros, entretanto, sugerem examente o inverso. Afirmam que os pais têm a tendência se implicarem mais fortemente quando seus filhos demonstram um rendimento escolar mais fraco ou quando, ao realizar a lição de casa, solicitam a ajuda de seus pais (CLARK, 1993; HOOVERDEMPSEY ET AL., 2001; WALKER, HOOVER-DEMPSEY, REED, \& JONES, 2000). Na mesma direção de idéias, Cooper (2001) conclui que a ajuda dos pais é crucial para os alunos que estão em situação de dificuldade escolar especialmente quando estes têm dificuldade em se concentrar e não conseguem gerir seu tempo de maneira adequada e, por isso, desenvolyemse menos.

\section{Motivação dos pais quando participam na realização da lição de casa}

Perguntamos: como explicar esta motivação? Alguns estudos foram realizados acerca dos motivos psicológicos deste posicionamento. Segundo Hoover-Dempsey e Sandler (1997), os pais se implicam nesta tarefa, dentre outras razões, por compreenderem a importância deste papel para seus filhos; porque se sentem competentes e ainda porque se sentem convidados pelos seus filhos ou pelos professores destes. Em um estudo realizado no Quebec sobre a implicação dos pais e mães nas lições de casa de seus filhos, os resultados colocaram em evidência a importância do sentimento de competência desses no momento da intervenção seguida da percepção que eles têm do convite para participar ou dos seus filhos ou dos seus professores. 
Todavia, este estudo não realizou especificamente uma ligação entre a implicação dos pais e a realização das lições de casa por seus filhos.

Este é o motivo que nos levou a realizar este estudo. Como explicar a implicação dos pais e mães? Até onde sabemos, nenhum estudo similar foi realizado no Brasil. E assim, questionamos: Como a cultura influencia na postura dos pais? Em outras, palavras, são os pais brasileiros implicados na realização das tarefas domésticas pelos mesmos motivos que os pais do Quebec? E com qual intensidade?

\section{Método}

\section{Participantes}

Descrição dos participantes no Quebec (ver Tabela 1)

$\mathrm{Na}$ amostra do Quebec, 44,0\% dos alunos de ensino fundamental envolvidos são meninas e $56,0 \%$, meninos. Constatamos que $62,2 \%$, dos alunos pertencem a famílias tradicionais (compostas pelos dois genitores) e $37,8 \%$ dos respondentes (pai ou mãe dos alunos) concluíram o Ensino. Médio e possuem escolarização superior a este nível de ensino.

Os alunos do ensino fundamental envolvidos neste trabalho que contam com dois adultos em suas casas perfazem 78,4\%, Em seguida, $53,5 \%$ têm cineo adultos nos seus lares. Cabe destacar que $18,8 \%$ contam com um adulto em casa; $1,6 \%$, com três; $1,2 \%$ com quatro e nenhum dos entrevistados mora com seis adultos na mesma unidade doméstica.

Finalmente, destacamos que no âmbito desta coleta de dados 38,0\% apresentam dificuldades escolares enquanto que 62,0\% afirmam ter sucesso na escola.

Descrição dos participantes no Brasil, cidade de São Paulo (ver Tabela 1) 
Na cidade de São Paulo, 59,2\% dos alunos de ensino fundamental envolvidos são meninas e 40,8\%, meninos. Constatamos que 74,2\% dos alunos pertencem a famílias tradicionais (compostas pelos dois genitores) e 60\% dos respondentes (pai ou mãe dos alunos) concluíram o Ensino Médio e possuem escolarização superior a este nível de ensino.

Os alunos do ensino fundamental envolvidos neste trabalho que contam com dois adultos em suas casas perfazem 47,8\%. Cabe destacar que $13,4 \%$ contam com um adulto em casa; $23,9 \%$, com três; $7,5 \%$ com quatro; $4,5 \%$ com cinco e apenas $3 \%$ com seis adultos no lar.

Finalmente, destacamos que no âmbito desta coleta de dados $33,9 \%$ apresentam dificuldades escolares enquanto que $66,1 \%$ não apresentam.

\section{Instrumentos de medida}

Vejamos os coeficientes de alpha de Cronbach obtidos por meio do estudo das duas amostras deste estudo referentes aos três fatores (“Compreensão do papel de pai ou mãe no âmbito da ajuda na realizaçãó das lições de casa", "Sentimento de competência parental" e "Representação de convite para participar que vem dos professores"2) que podem motivar os pais a participarem na realização das lições de casa dos seus filhos, assim como, o coeficiente de alpha de Cronbach.

1- Compreensão do papel de pai ou mãe no âmbito da ajuda na realização das lições de casa

Esta escala é baseada no Thinking about My Child's Homework (HOOVER-DEMPSEY e outros, 1995; WALKER e outros, 2000). Ela compreende 15 enunciados que descrevem a participação dos pais na

\footnotetext{
${ }^{2}$ Estas medidas foram utilizadas anteriormente no âmbito das pesquisas realizadas por Deslandes e Bertrand (2005, 2005). Neste estudo, elas adaptaram o instrumento para o domínio específico da realização das lições de casa.
} 
realização das lições de casa. Exemplo: "Eu questiono meu filho acerca da realização das suas lições de casa». O participante responde em uma escala do tipo Likert de (0) jamais a (3) sempre.

Os resultados da análise dos itens da escala de medida da compreensão do papel de pais se encontram na Tabela 3. O coeficiente alpha de Cronbach por amostra do Quebec é igual a 0,88 e o do Brasil corresponde 0,85 , dois valores muito satisfatórios. A escala compreende exatamente a 12 enunciados que são indênticos tanto no Brasil como no Quebec. As correlações item-total corrigidas se situam 0,33 e 0,72 para o Quebec, e 0,40 e 0,71 para o Brasil.

\section{2- Sentimento de competência parental}

O sentimento de competência dos pais para ajudar seus filhos na realização das tarefas é medido a partir de uma escala com seis enunciados (adaptado de BASSLER e BUROW, HOOVER-DEMPSEY, 1995 por DESLAND e BERTRAND, 2004, 2005). Exemplo de enunciado: "Eu sei como ajudar meu filho em seus deveres e lições $\square$. O pai ou a mãe indica numa escala de quatro pontos em que o um significa «fortemente em desacordo » e o quatro, «fortemente de acordo ». O valor do coeficiente alpha de escala de medida do sentimento de competência parental mostra-se satisfatório, sendo igual a 0,86 para a amostra do Quebec 0,81 , para a brasileira. A escala é composta de quatro enunciados e as correlações, itemtotal, corrigidas vão de 050 a 0,86 para a amostra do Quebec e 0,56 a 0,81 para a brasileira.

\section{3- Convite para participar que vem dos professores}

Este questionário é procedente do Parent Perceptions of Teacher Invitations to Involvement (Reed e outros, 2000) que, por sua vez, desenvolveu, a partir dos trabalhos de Epstein e de seus colegas (EPSTEIN, 1986; EPSTEIN e outros, 1994). Esta categoria comporta seis enunciados. Os pais indicam, em uma escala de quatro pontos em que um indica « fortemente em desacordo » e quatro, «fortemente de acordo ». A escala 
que mediu a percepção dos pais acerca do convite à participação feito pelos professores é composta por sete enunciados nos qual as correlações itemtotal corrigidas variam entre 0,64 e 0,90 (para o Quebec) e 0,71 e 0,92 (para o Brasil). Exemplo: «O professor me pede para ajudar meu filho a gerir seu tempo enquano faz sua lições de casa ». As possibilidades de escolha variam entre (0) jamais a (3) sempre.

De acordo com Silva e outros (2008), o coeficiente alpha de Cronbach tem valor satisfatório, entre 0,90 e 0,92 respectivamente.

Participação dos pais nas lições de casa

$\mathrm{O}$ instrumento de medida da participação dos pais no que se refere à realização das lições de casa é composto por 12 enunciados com um coeficiente alpha de Cronbach igual a 0,88 para a amostra do Quebec e 0,85 , para a brasileira. As correlações item-total corrigidas se situam entre 0,33 e 0,72 (Quebec) e 0,40 e 0,75 (Brasil).

Em seguida, apresentaremos as características das crianças participantes deste estudo, das suas famílias e das condições sóciodemográficas em que vivem.

\section{Características individuais das crianças}

Sexo da criança: o pai indica se a criança é menino ou menina.

Rendimento escolar da criança: Os pais devem indicar se a criança:

(a) tem dificuldades importantes na escola; (b) tem pequenas dificuldades;

(c) se sai bem; (d) se sai muito bem (medidas utilizadas por Deslandes \& Bertrand, 2004, 2005). Os dados foram codificados novamente da seguinte maneira: (0) tem dificuldades; (1) se saem bem ou muito bem. Esta nova codificação foi necessária na medida em que havia um fraco número de participantes em determinadas categorias das respostas.

\section{Características sócio-demográficas}

Nível de escolaridade do respondente. O pai indica o maior nível de estudo que completou: (1) estudos primários; (2) estudos de ensino médio; (3) estudos profissionais (nível médio); (4) estudos preparatórios para o 
vestibular; (5) estudos universitários. As respostas foram codificadas novamente da seguinte maneira: (1) estudos secundários ou menos; (2) estudos depois do ensino médio e, (3) estudos universitários. Ressaltamos que, para fins desta análise, as respostas foram codificadas novamente em : 1) Até o ensino médio e 2) após o ensino médio.

Estrutura familiar: O pai ou mãe deve indicar a qual tipo de família pertence: (1) tradicional; (2) monoparental; (3) reconstituída; (4) guarda partilhada. As respostas foram agrupadas com a seguinte classificação: (0) tradicional ou (1) não tradicional.

Número de adultos em casa. Um dos pais deve indicar o número de adultos que vivem na mesma casa. A questã̉o 'é aberta.

\section{Procedimentos}

No Quebec, os questionários para os pais foram traduzidos por um especialista em lingüística. Dois pesquisadores trabalharam conjuntamente com a finalidade de julgar e esclarecer a pertinência das questões e de seus enunciados. Os questionários foram validados junto com pais que não faziam parte das amostras dessa pesquisa. O objetivo desta validação foi determinar se os enunciados destinados aos pais eram claros, redigidos sem ambigüidađe e-ainda numa-lingtagem usada no meio escolar. Os respondentes, que tiveram interesse de participar deste processo de validação, tiveram com tarefa ler o questionário e levantar aspectos problemáticos. Eles não precisam responder ao questionário, mas deveriam fazer uma avaliação do tempo que levariam para tanto. Os membros da equipe de pesquisa identificaram cinco pais para participarem deste processo de validação. A avaliação da clareza dos enunciados do questionário destinado aos pais foi finalmente realizada por quatro pais de alunos do ensino primário. Depois de obter conhecimento das recomendações e de seus comentários, alguns ajustes mínimos foram feitos 
para clarificar os enunciados e as questões antes de chegar à versão final do instrumento que foi utilizada no âmbito desta enquete.

Em seguida, foram aplicados 250 questionários a 250 pais de alunos do quarto ano primários.

Na cidade de São Paulo, tal instrumento foi lido, compreendido e discutido por dois grupos de alunos envolvidos na aplicação do mesmo: alunos de graduação em Pedagogia da mesma instituição de ensino superior do período verspertino e do período noturno. Os dados foram coletados nas escolas em que os estudantes realizam seus estudos e, majoritariamente, no momento em que os alunos faziam aulas de língua portuguesa. Neste contexto, durantes os meses de agosto, setembro, outubro e novembro de 2007, foram aplicados 71 questionários na cidade de São Paulo para país ou mães de alunos entre 10 e 11 anos, majoritariamente, de escolas públicas.

Em seguida, uma pesquisa foi realizada para determinar as qualidades metrológicas de quatro instrumentos de medida utilizados juto às duas amostras em que foram realizadas esta pesquisa, uma no Quebec e outra na cidade de São Paulo, Brasil.

Globalmente, os resultados mostram que os índices metrológicos de cada um destes instrumentos são equivalentes nas duas amostras.

\section{Resultados}

O objetivo do estudo consistiu em examinar os fatores explicativos da participação dos pais na realização das lições de casa no Quebec e no Brasil. Vários foram os fatores colocados em evidência para tanto: as características individuais e familiares, o número de adultos na casa e ainda a compreensão do papel de pais, do sentimento de competência e os convites feitos aos pais pelos professores para que participassem da realização da lição de casa de seus filhos.

Médias e ecarts-types para as variáveis do estudo 
Os resultados das análises descritivas aparecem na Tabela 2. No Quebec, o score mais elevado está ligado ao sentimento de competência dos pais (2,28 / 3) enquanto que no Brasil, os scores mais elevados estão associados ao sentimento de competência parental $(2,07 / 3)$ e à compreensão do papel de pai ou mãe (2,07 / 3). Além disso, os scores mais fracos são associados ao convite da parte dos professores para que os pais participem na realização das lições de casa (Quebec: 0,76 / 3; Brésil: 1,20 / 3.).

\section{Tabela 2}

\section{Relação entre as variáveis de estudo}

Das correlações de Pearson calculadas entre as diferentes variâveis do estudo (tabela 3), obtivemos como associações positivas, nos dois meios estudados, entre a participação dos pais de um lado e a compreensão do papel de pai e mãe de outro $(r=0,50 ; p<0.01$; no Quebec et $r=0,40$; $\mathrm{p}<0,01$ no Brasil); constatou-se também a existência de um grau médio entre a participação dos pais e o seu sentimento de competência (no Quebec : $r=0,22, p<0,01$; no Brasil: $r=0,27, p<0,01$ ). Uma associação mais forte foi observado do lado brasileiro comparativamente ao Quebec no que diz respeito à relação entre o sentimento de competência dos pais e a participação destes na realização das lições de casa de seus filhos (no Quebec : $r=0,26, p<0,01$; no Brasil : $r=0,49$, $p<0,01$ ).

\section{Tabela 3}

Análises de regressão sobre a participação dos pais na realização

\section{das lições de casa}

Para identificar as variáveis preditivas da participação dos pais na realização das lições de casa dos seus filhos, duas séries de análises de 
regressão múltiplas hierárquicas foram realizadas para o Quebec e para o Brasil. Num primeiro tempo, as variáveis contextuais individuais e familiares (sexo da criança, rendimento escolar, estrutura familiar e escolaridade do pai que respondeu ao questionário e ainda o número de adultos que vivem na mesma casa como variáveis controle (modelo 1). Em seguida, as variáveis psicológicas preditivas da participação dos pais (modelo 2) foram juntadas (compreensão do papel de pais e mãe, sentimento de competência e a percepção acerca dos convites feitos pelos professores aos pais para que esses participem na realização das lições de casa) segundo um procedimento seqüencial passo a passa (Stepwise). Estas análises de regressão foram feitas independentemente para o Quebec e para o Brasil.

A tabela 4 apresenta a proporção explicada pelos modelos de regressão ( $R$ Square). Os resultados indicam que a proporção da variância explicadas pelas variáveis contextuais individuais e familiares são mais elevadas para o Brasil $(10,9 \%)$ do que para o Quebec $(5,7 \%)$. Além disto, juntar as variáveis psicológicas preditivas aportam uma maior proporção de variância explicada para o Brasil (a proporção de $10,9 \%$ a $45,6 \%$ ) em relação ao Quebec (a proporção passa de 5,7\% à 33,7\%).

A_observação destes valores de coeficientes daş equações de regressão (tabela 4) revela similitudes entre o Quebec e o Brasil. De fato, nos dois meios, a única variável significativa tratou do rendimento do aluno, entretanto a relação não possuía o mesmo significado. Além disto, mais os jovens de Quebec vão bem na escola, menos os seus pais se implicam na realização das lições de casa (Bêta $=-0,165 ; \mathrm{p}<0,01$ ) enquanto que no Brasil, observamos o inverso (Bêta $=-0,285 ; \mathrm{p}<0,05$ ). Qualquer que seja o sexo da criança, a estrutura familiar, o nível de escolaridade do respondente e o número de adultos na casa, os pais do Quebec e do Brasil parecem se implicar no âmbito da realização dos deveres de casa de um modo idêntico. 
No que concerne ao modelo 2 que inclui as variáveis psicológicas e ainda o rendimento escolar da criança, a variável psicológica que parece predizer a maior participação dos pais corresponde à compreensão do papel de pai e de mãe na amostra do Quebec (Bêta $=0,438 ; \mathrm{p}<0,001$ ) e ao sentimento de competência dos pais na amostra brasileira (Bêta=0, 369 ; p < 0,01 no Québec). A segunda variável psicológica que contribui sobremaneira é o sentimento de competência dos pais que vem em segundo lugar na importância preditiva no Quebec (Bêta=0,154; p < 0,01) e a compreensão do papel de pai e mãe, no Brasil (Bêta=0, $224 ; \mathrm{p}<0,05)$. A variável correspondente aos convites dos professores, ainda que significativa junto às amostras estudadas, mostra um poder preditivo mais elevado para a amostra brasileira (Bêta $=0,320 ; \mathrm{p}<0,01)$ do que para a do Quebec (Bêta=0, 121; $\mathrm{p}<0,05)$. É importante precisar que exceto as variáveis psicológicas, o rendimento da criança é uma variável predifiva no segundo modelo mostrando poder preditivo mais forte no caso da amostra brasileira (Brésil: Bêta $=0,313 ; \mathrm{p}<0,003$ ) (Quebec:Bêta=-0,164; $\mathrm{p}<0,05$ ).

\section{Díscussão}

O presente estudo pretendeu identificar as variáveis preditivas da participaçãô - dos pais no âmbito das tições de casa (na escola primária, no Quebec; quarto, quinto e sexto ano do ensino fundamental no Brasil) e verificar as diferenças e similitudes concernantes às representações dos pais destes alunos. Tentamos encontrar elementos para a resposta das seguintes questões : «O que motiva os pais, tanto no Brasil como no Quebec, a participar na realização das lições de casa dos seus filhos?”. "Em que estas razões se assemelham ou se diferenciam em função dos diferentes meios de estudo em pauta?"

Diferenças entre os pais no Quebec e no Brasil 
Os resultados mostram que os pais do Quebec se implicam na realização das lições de casa dos seus filhos, sobretudo, si estes têm dificuldades na escola. De modo oposto, os pais brasileiros tendem a fazê-lo se os filhos se saem melhor na escola. Do mesmo modo, os pais brasileiros se implicam, especialmente, se eles se sentem competentes para tanto. É plausível pensar que os pais brasileiros de crianças que apresentam dificuldades na escola não sabem exatamente o que eles precisam fazer para ajudar seus filhos ou que eles não compreendem bem o que devem fazer para ajudá-los. Estes resultados vão na mesma direção dos resultados de Carvalho (2000) que sustentam que muitos pais brasileiros, sobretudo, as mães, não sabem o que precisam fazer para ajudar seus filhos.

Além do aspecto considerado acima, outras três diferenças forram encontradas entre os pais envolvidos nas duas amostras do nosso estudo. A saber:

1- Na amostragem brasileira, as variáveis psicológicas são mais importantes na explicação da implicação dos pais que no caso dos pais do Quebec.

2- Outro resultado interessante é a importância demonstrada pela compreensão dos pais do Quebec de suas responsabilidades como pais no âmbito da explicação da sua implicação no acompanhamento da realização das lições de casa. Em outras palavras, os pais do Quebec se sentem mais responsáveis, no sentido de se implicarem na realização das lições de casa, do que os pais brasileiros.

3- Finalmente, uma última diferença é observada nas duas amostras quando ao poder explicação dos convites para participar na realização dos deveres de casa provenientes dos professores. Este poder é muito mais importante junto aos pais do Quebec do que junto aos brasileiros.

Levando em considerações estas três tendências acima apontadas referentes às diferenças entre os pais no Brasil e no Quebec, deparamo-nos com aspectos subjetivos dos sujeitos envolvidos nesta pesquisa. Assim, 
nestes três casos, entendemos que um estudo qualitativo, especificamente com este recorte têmporo- espacial- poderia nos permitir a elaboração de inferências adequadas acerca desta tendência. Isto porque, de acordo com Popy \& Mays (1995), os métodos quantitativos e qualitativos não são contraditórios, pelo contrário, quando usados com discernimento podem esclarecer o fenômeno em pauta. E ainda, de acordo com Duffy (1987), tal procedimento: 1- Pode minimizar possíveis vieses próprios dos métodos estatísticos; 2- Congrega e identifica variáveis específicas à luz do todo que está sendo estudado; 3- Pode completar um conjunto de fatos e causas associados ao emprego de uma metodologia quantitativa com uma visão dinâmica da realidade; 4- Possibilita enriquecer constatações obtidas sob condições controladas com dados obtidos no contexto natural da ocorrếncia e, finalmente; 5- Apresenta a possibilidade de confirmar a validade e a confiabilidade das descobertas das técnicas empregadas até então.

No caso do nosso estudo, poderíamos lançar mão de alguns aspectos do método autobiográfico: o conhecimento da vida e a respectiva escrita desta dos pais envolvidos nesta pesquisa; o estudo de materiais escolares que possam esclarecer nossas questões; a coleta de depoimentos; entrevistas, dentre outros instrumentos.

Nesta direção, podemos levantar algumas suposições. Dentre elas, destacamos que é possível que no Quebec, tendo em vista o atual e intenso debate acerca da temática da lição de casa- mesmo porque, frente à realidade social que se impõe aos moradores desta região canadense, a saber: constituição crescente de famílias monoparentais, ausência das mães em casa e a inserção destas no mercado de trabalho extremamente competitivo- os pais tenham introjetado o "fazer a lição de casa" como uma das tarefas inerentes ao papel de pai. Por outro lado no Brasil, talvez, pela falta da implementação de políticas públicas nesta direção, o "ser competente" aparece como um fator mais forte no sentido de explicar o engajamento dos pais junto aos seus filhos para a realização das lições de 
casa. E, ainda, tendo em vista, estas mesmas diferenças culturais, apontamos a necessidade de investigar se a menor aceitação dos pais brasileiros frente aos convites para a implicação dos pais na realização das lições de casa se deve ao fato de, pelo menos, um dos seguintes fatores: a baixa incidência de convites por partes dos professores ou ainda a baixa resposta dos pais frente a possíveis convites tendo em vista a crescente desvalorização da profissão professor enfrentada pelos docentes no Brasil (cf. FRIGOTTO, 2003).

\section{Similaridades entre os pais brasileiros e do Quebec}

Um dos limites do nosso estudo foi o tratamento, tamanho e a composição das nossas amostras. No caso brasileiro, em particular, tivemos um número menor de participantes. Além disto, os pais que compuseram as amostras desta pesquisa o fizeram de forma espontânea. Deste modo, não temos a pretensão que tais amostras sejam representativas de todos os pais e mães do Brasil e do Quebec. Constatou-se também que os pais pertencentes aos dois meios de estudo desta pesquisa parecem não ser influenciados pelas características sócio-demográficas familiares. Nenhuma ligação foi encontrada no nível da estrutura familiar, no nível de escolaridade dos pais e no número de adultos que vivem na mesma casa junto com a criança As variáveis contextuais das famílias não interferem na implicação dos pais no sentido de se implicarem ou não no acompanhamento da realização das lições de casa de seus filhos. Neste ponto, perguntamos: quais são os fatos “ocultos" pelos dados coletados e pelas análises estatísticas feias a partir da amostra de pais, alunos e professores brasileiros na cidade de São Paulo? Alguns outros dados coletados pelo Instituto Brasileiro de Geografia e Estatística (IBGE) (2000), podem nos servir para iluminar estas questões e nos permitir fazer inferências consideráveis. Vejamos abaixo:

O Censo Demográfico 2000- realizado pelo IBGE- o Brasil, com 8 514 215,3 km2, composto por 27 Unidades da Federação e 5507 municípios- atingiu um total de 54265618 de domicílios e obteve que:

- Total de habitantes no Brasil: 169872856 
- Total de habitantes no estado de São Paulo (estado mais rico do Brasil): 39.827 .570

- Total de habitantes da cidade de São Paulo (cidade mais rica do Brasil): 10.886 .518

- Matrícula - Ensino fundamental no ano de 2007: 1.591.536 alunos

- Matrícula - Ensino médio (2007) 457.680 alunos

- Matrícula - Ensino superior - 2005 (2) 429.079 Matrículas

- Matrícula Universidade de São Paulo- em torno de 10.000 vagas

Ou seja, a amostra da nossa pesquisa é proveniente de um dos estratos sociais mais privilegiados da sociedade brasileira. Dito de outro modo, os sujeitos desta pesquisa pertencem ao estado mais rico da União, da cidade mais próspera e ainda pertencem ao raio de atuação dos alunos ingressantes da universidade que atende também aos mais privilegiados da sociedade brasileira. E ainda, esta amostra poderia representar, se fosse o caso, apenas, aproximadamente, $28 \%$ dos alunos brasileiros, aqueles que conseguem passar por todas as barreiras de permanência na escola no Ensino Fundamental. E, dentre estes, finalmente, nossa amostra diz respeito àqueles que estão no raio de atuação de, aproximadamente, $0,63 \%$ da população nacional, ou seja, alunos da Universidade de São Paulo.

\section{Conclusão}

Este estudo teve como objetivo identificar as variáveis individuais, contextuais e psicológicas preditivas da participação dos pais do Quebec e do Brasil no âmbito da realização das lições de casa. Os modelos obtidos para as duas amostras compreenderam três variáveis psicológicas- a compreensão do papel de pais e mãe, o sentimento de competência e a percepção frente ao convite de professores para participar das lições de casa- com uma maior importância acordada para a amostra de pais do Quebec e para a segunda amostra brasileira. O rendimento escolar do aluno, 
que deve ser levado em consideração também, mostra, entretanto, uma relação inversa nas duas amostras estudadas. Os brasileiros se implicam mais quando o filho se sai melhor na escola enquanto que os canadenses o fazem se os filhos apresentam mais dificuldades na escola. Em suma, os pais do Quebec têm maior tendência a participar se eles compreendem que isto faz parte das suas responsabilidades de pai e mãe, si seus filhos têm dificuldades e se eles recebem convites dos professores para tanto.

Do lado brasileiro, os pais e mães estudados decidem por se implicar, antes de mais nada, se eles se sentem competentes, se eles percebem os convites dos professores e se seus filhos se saem bem na escola e se eles compreendem que tal envolvimento faz parte da responsabilidade do papel de pai e de mãe. Além disto, esta reflexão mostra que os dados aqui analisados refletem uma pequena parte da sociedade brasileira, talvez, aquela que é mais semelhante ao Quebec em termos de situação econômica, social e educacional. E assim, o que nossa coleta de dados e análise não mostra explicitamente, apesar de nos fazer ver: a brutal exclusão da sociedade brasileira e para além desta constatação, conforme nos aponta Angelucci e outros (2004), quando trata do estado da arte quanto à temática do "fracasso escolar", muito deve ser feito, refletido e tomado seriamente. Em suma,_o "fracasso escolar" no Brasil, assim como a questão da implicação dos pais na realização das lições de casa dos seus filhos, precisam se afastar da culpabilização das crianças e de seus pais. Por isso, talvez, os pais do Quebec se implicar MAIS nos deveres de casa dos seus filhos quando estes apresentam dificuldades na escola do que os pais brasileiros. Infelizmente, no Brasil, tendo em vista os dados apresentados, “ter fracasso escolar" é a regra GERAL e pouco pode ser feito. Por outro lado, no Quebec, “o sucesso na escola" é o mais comum- e há condições sociais para isto, valendo à pena, portanto, o envolvimento dos pais quando seus filhos têm problemas na escola, pois, provavelmente, tratar-se-á de uma questão de fundo individual. Assim como no Brasil, quando uma criança vai 
bem na escola - ou seja, foge à regra social- ela se torna o centro de atenções da família, até mesmo a esperança da família de que ela se torne uma alavanca para a promoção social do grupo numa sociedade marcada por astros, estrelas e ídolos, todos exceções quando pensados no contexto geral da sociedade brasileira, fazendo com que seus pais se impliquem mais na realização das lições de casa no âmbito da vida privada.

Finalmente, do ponto de vista da realização da pesquisa de campo, tanto no caso brasileiro como no caso do Quebec, a coleta de dados não tem sido uma tarefa simples e rápida de ser realizada frente aos diversos consentimentos que precisam ser obtidos: das instâncias nas diferentes universidades e nas unidades escolares; dos pais, professores e profissionais da escola e mesmo dos alunos. Esta cadeia de solicitação de consentimentos, muitas vezes, nos faz compor nossas amostras de estudo com certo viés tendo em vista que, especialmente no caso desta pesquisa, envolvidos neste tipo de trabalho e que se encontram dispostos a colaborar a priori estão mais disponíveis para a execução de trabalho coletivo- família, escola e comunidade- para a realização das lições de casa.

\section{Referências bibliográficas}

AMES, Carole., de STEFANO, Lizanne, WATKINS, Thomas \& SHELDON, Steven (1995). Teacher's school-to-home communications and parent involvement: The role of parent perceptions and beliefs (Report 28). Baltimore, MD: Johns Hopkins University, Center on Families, Communities, Schools, and Children's learning.

ANGELUCCI, Carla Biancha ET al (2004). O estado da arte da pesquisa sobre o fracasso escolar (1991- 2002): um estudo introdutório. In: Educação e Pesquisa, São Paulo, v. 30, n. 1, p. 51-72, jan./ abr. 2004.

BORG, Walter R. \& GALL, Meredith Damien (1989). Educational Research. An Introduction. NY: White Plains. 
CARVALHO, Maria Eulina Pessoa (2000). Relações entre família e escola e suas implicações de gênero. In: Cadernos de Pesquisa, São Paulo, ${ }^{\circ}$ 110, p. $34-45$.

CLARK, Reginald M. (1993). Homework-focused parenting practices that positively affect student achievement. In: CHAVKIN, Nancy Feyl (Org.). Families and schools in a pluralistic society. Albany: State University of New York Press, p. 85- 105.

COOPER, Harris (2001). The battle over homework. Common ground for administrators, teachers and parents. Thousand Oaks, CA: Sage.

COOPER, Harris e al (2000). Homework in the home: How student, family and parenting style differences relate to homework process. In: Contemporary Educational Psychology, v. 25 (4), p. 464- 487.

CRESWELL, J. (1998). Qualitative Inquiry and Research. In: Design: Choosing among Five Traditions, Thousand Oaks, CA: Sage Publications. Gadamer.

CROCKER, Linda \& ALGINA, James (1986). Introduction to Classical and modern Test Theory. New York: CBS College Publishing.

DESLANDES, Rollande et BERTRAND, Richard (2005). Motivation of Parent Involvement in Secondary-Level Schooling. In: The Journal of Educational Research, Vol 98, n.3, January- February.

(2004). Motivation

des parentes à participer au suivi scolaire de leur enfant au primaire. In : Revué- des Sciences de l'Éducation, vol. XXX, n. 2, 2004, p. 411 a 433.

DUFFY, Mary E. (1987). Methodological triangulation: a vehicle for merging quantitative and qualitative research methods. In: Jornal of Nursing Scholarship, 19 (3), 1987, pp. 130-133.

EPSTEIN, Joyce. L. (2001a). School, family and community partnerships: preparing educators and improving schools. Boulder, CO: Westview Press.

EPSTEIN, Joyce. L. \& VAN VOORHIS, Frances L. (2001b). More then minutes: Teacher's role in designing homework. In: Educational Psychologist, 36 (3), 181-193. 
FRANCO, Olívia Carvalho de Mello. Práticas familiares em relação ao dever de casa: um estudo junto às camadas médias de Belo Horizonte. 115 f. Dissertação (Mestrado)- Faculdade de Educação da Universidade Federal de Minas Gerais, 2002.

FRIGOTTO, Gaudêncio. (2003). Educação e Crise do Capitalismo Real. São Paulo: Cortez.

GILL, Brian P., and SCHLOSSMAN, Steven L. (2003). Homework and the Elusive Voice of Parents: Some Historical Perspectives. In: Teachers College Record 105, no. 5.

GROLNICK, Maarten Vansteenkiste Wendy. S. \& RYAN, Maria L.. (1989) Parent styles associated with children's self-regulation and competence in school. In: Journal of Psychology, 81 (2), p. 143-154.

HOOVER-DEMPSEY, Kathleen Virginia; BASSLER, Otto C. e BURROW, Rebecca. (1995). Parents' reported involvement in students' homework: strategies and practices. In: The Elementary School Journal, p. $436-450$.

INSTITUTO BRASILEIRO DE GEOGRAFIA E ESTATÍSTICA. CENSO BRASIL 2000. http://www.ibge.gov.br. Acesso em: 12 nov. 2009.

JOÃO PESSOA, Secretaria de Educação e Cultura. http://www.joaopessoa.pb.gov.br/secretarias/sedec/. Acesso em: 15 out. 2007.

KRAMER, Sonia (2003). Política do Pré-escolar no Brasil: a arte do disfarce. São Paulo: Ed. Cortẹz.

LAREAU, Annette (1987). Social class differences in family-school relationships: The importance of cultural capital. In: Sociology of Education, 60 (2), p. 73-85.

LUZ, Madel Theresinha. (2000). Duas questões permanentes em um século de políticas de saúde no Brasil republicano. In : Revista Ciência e Saúde coletiva, v. 2, n5, p. 293- 312, 2000.

MARJORIBANKS, Kevin. Family Environments and Children's Outcomes. In Educational Psychology, Vol. 25, No. 6, December 2005, p. 647-657. 
MINISTÈRE DE L'ÉDUCATION, DU LOISIR ET DU SPORT [MELS]. (2008). Évaluation de programme. Programme aide aux devoirs. Québec, Gouvernement du Québec.

MINISTÉRIO DA EDUCAÇÃO, INEP, (2003). Brasília: Sala de Imprensa - Notícias do SAEB. In: http://www.inep.gov.br. BRASIL, Ministério da Educação, SEF, (2002). Educar é uma tarefa de todos nós. Um guia para a família participar, no dia-a-dia, da educação de nossas crianças. Brasília: Secretaria de Ensino Fundamental, Assessoria Nacional do Programa Parâmetros em Ação.

PATALL, Erika Alisha, COOPER, Harris e ROBINSON, R. (2007). Parental involvement in homework: a research synthesis. IN: THE ANNUAL EDUCATIONAL RESEARCH ASSOCIATION MEETING (AERA), Chicago IL.

PATTO, Maria Helena Sousa (1997). Por uma crítica da razão psicométrica. In Revista Psicologia, v. 8. São Paulo: EDUSP.

PAULA, Flávia Anastácio de. Lições, deveres, tarefa, para casa: novas e velhas prescrições para professoras. 154 f. Dissertação (Mestrado)Faculdade de Educação da Universidade de Campinas, 2000.

POPE, Catherine; MAYS, Nick. Reaching the parts other methods cannot reach: an introduction to qualitative methods in health and health service research, In British Medical Journal, n. 311, 1995, pp. 42-45.

REED, Richard P., JONES, Kathleen P., WALKER, Joan_M. - . \& HOOVER-DEMPSEY, Kathleen Virginia (2000, April). Parents' motivations for involvement in children's -education: Testing a theoretical model. Paper presented at the annual meeting of the American Educational Research Association, New Orlean, LA.

SHELDON, Steven B. (2002). Parents' social networks and beliefs as predictors of parent involvement. In: The Elementary School Journal, 102 (4), 301-316.

WALKER, Joan M. T., HOOVER-DEMPSEY, Kathleen. V., WHETSEL, D. R. \& JONES, Kathleen P. (2004). Parental involvement in homework: A review of current research and its implications for teachers, after school. program staff, and parental leaders. In: http:www.gse.harvard.edu/hfrp/projects/fine/resources/research/homework. html. Acessado em 16 jul. 2007. 
TATSUOKA, Maurice M. (1988). Multivariate Analysis. New York: Macmillan Publishing Company.

XU, Jianzhong e CORNO, Lyn (2003). Family help and homework management reported by middle school students. In: The Elementary School Journal, n. 103, p. 503-536.

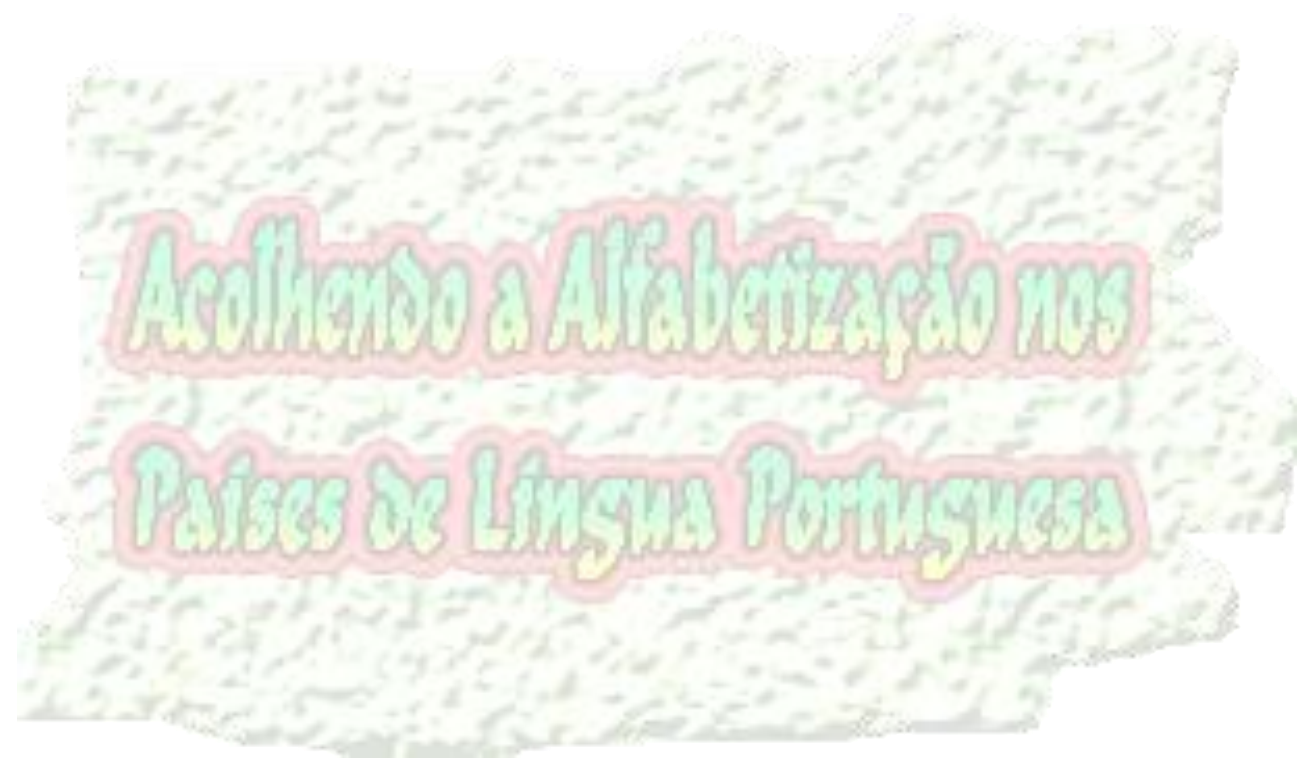


Tabela 1 :

Características individuais e sócio-demográficas:

\begin{tabular}{|c|c|c|c|}
\hline & & Quebec & Brasil \\
\hline $\begin{array}{l}\text { Características } \\
\text { demográficas }\end{array}$ & sócio- & $\%$ & $\%$ \\
\hline
\end{tabular}

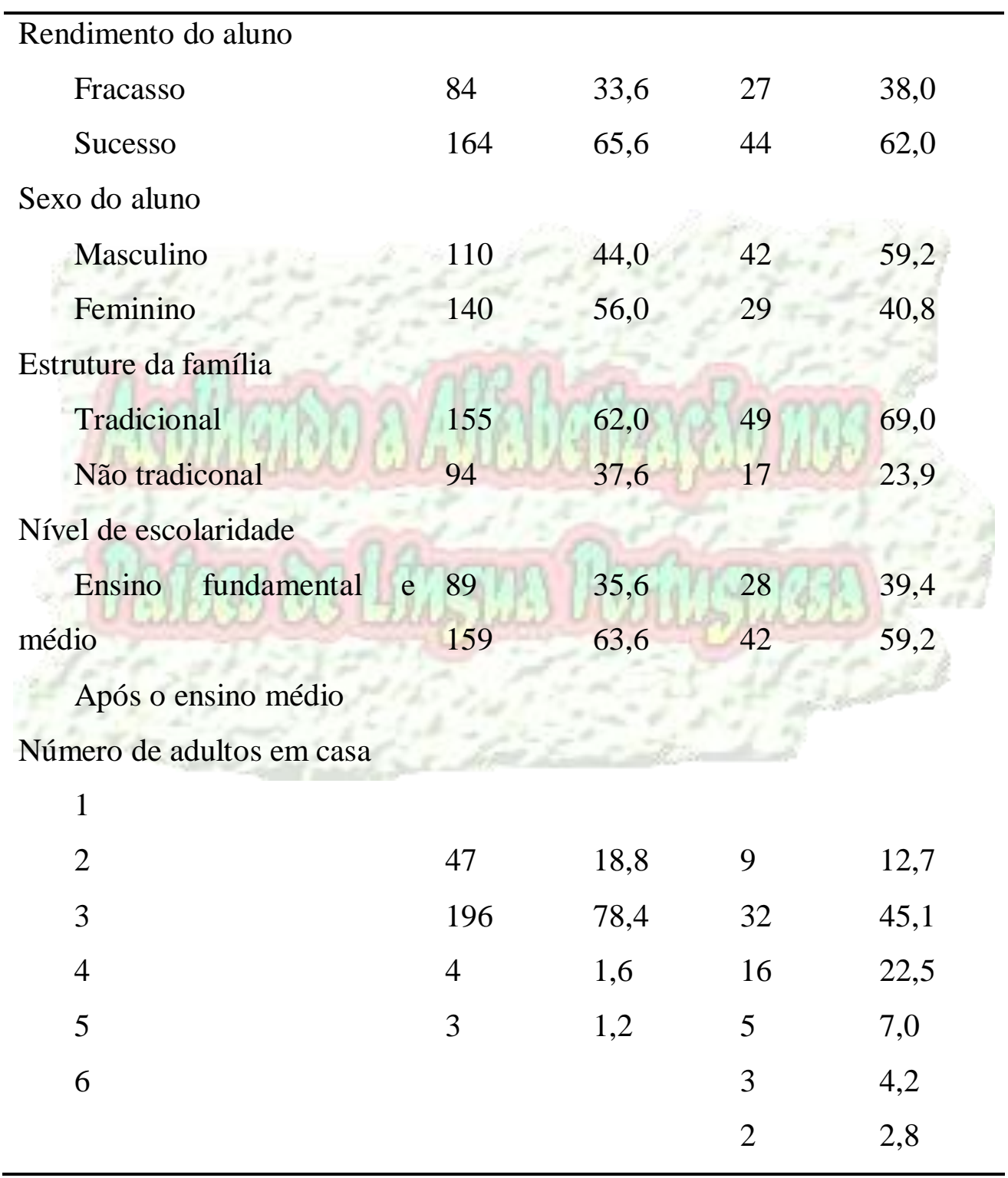


Tabela 2:

Médias e écarts-types para as variáveis do estudo.

\begin{tabular}{llllll}
\hline \multirow{2}{*}{ Variáveis } & \multicolumn{2}{c}{ Médias } & \multicolumn{2}{l}{ Ecarts-types } \\
\cline { 2 - 5 } & & Quebec & Brasil & Quebec & Brasil \\
\hline Participação dos pais na & 2,12 & 2,01 & 0,52 & 0,66 \\
realização dos deveres & & & & \\
\hline Compreensão do papel de pai/ & 2,16 & 2,07 & 0,40 & 0,63 \\
mãe & & & & \\
\hline Convite dos professores & 0,76 & 1,20 & 0,81 & 0,93 \\
\hline Sentimento de competência de & 2,28 & 2,07 & 0,52 & 0,71 \\
ser pai/ mãe & & & & & \\
\hline
\end{tabular}


Tabela 3:

Matriz de correlações Pearsons para as variáveis do estudo

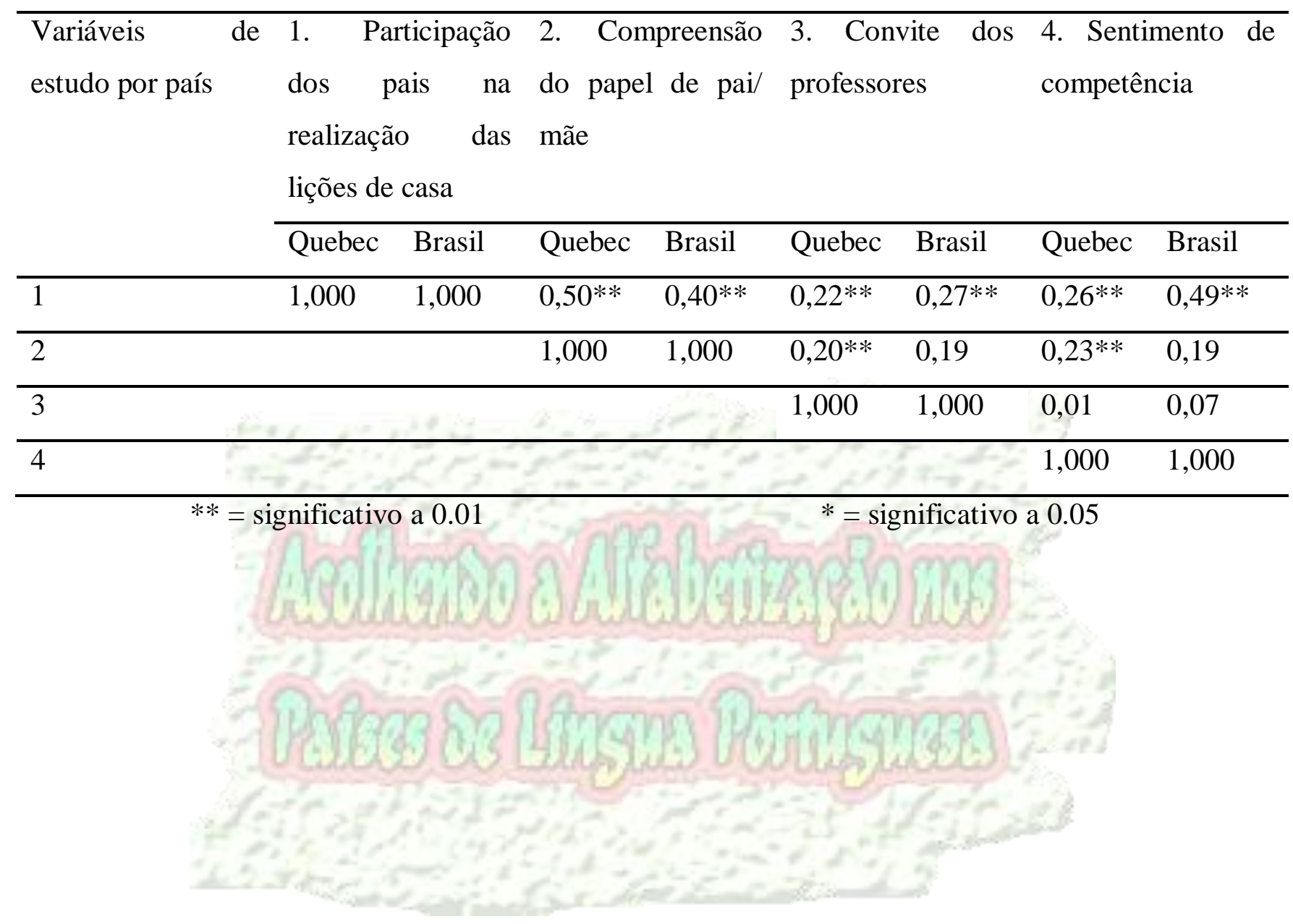


Tabela 4 :

Analises de regressão sobre a participação dos pais na realização das lições de casa

\begin{tabular}{llllll}
\hline Meio & Etapas & Variáveis & Bêta & $\mathrm{R}^{2}$ & $\mathrm{~F}$ \\
\hline & 1 & Rendimento &,$- 165^{* *}$ & 0,057 & $2,859^{*}$
\end{tabular}

Quebec

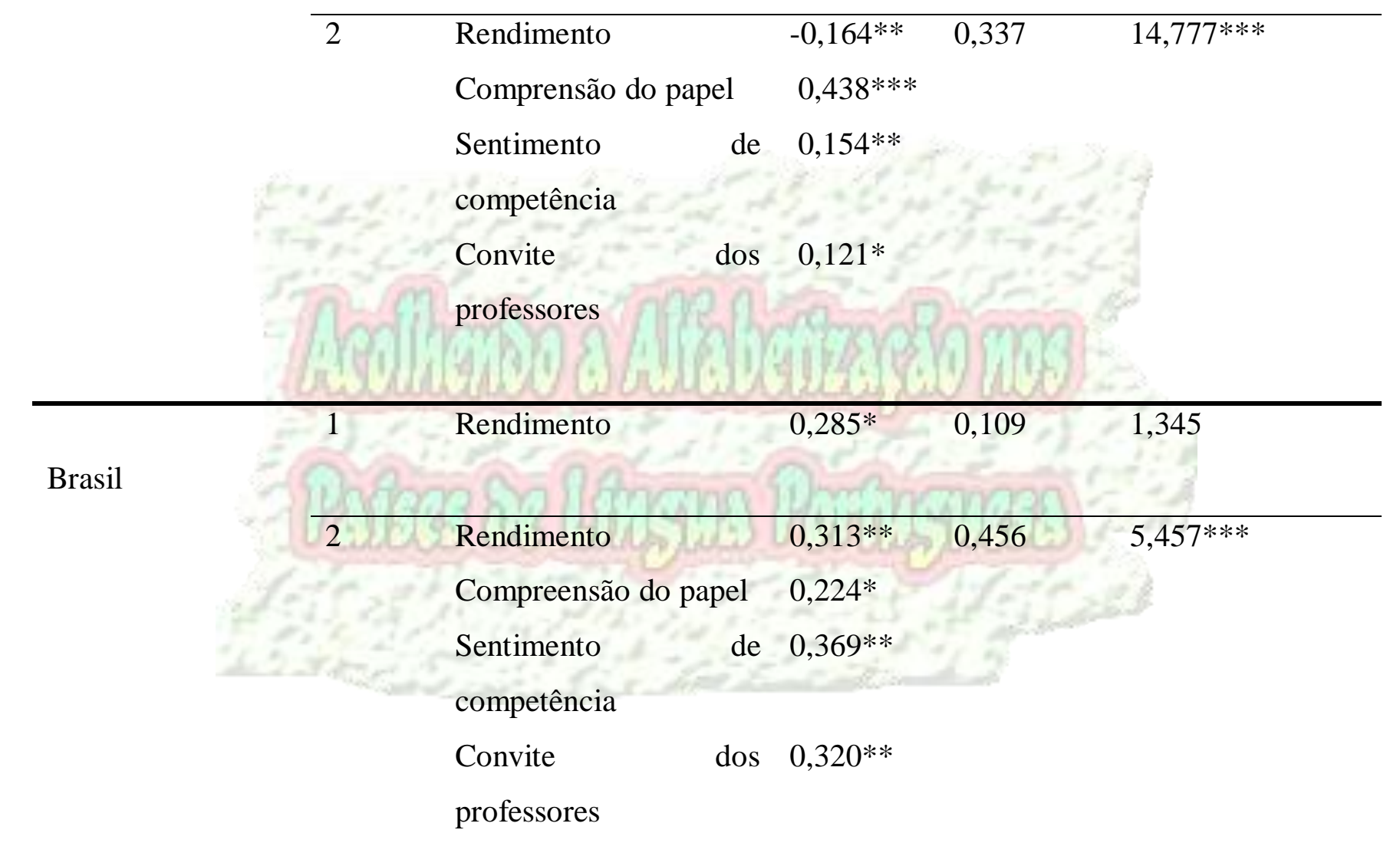




\section{Autores:}

Nilce da Silva

Professora da Universidade de São Paulo - Faculdade de Educação

Contato: nilce@usp.br

Michel Rousseau-

Pesquisador da Université du Québec à Rimouski

Contato: michel.rousseau@uqr.ca

Rollande Deslandes

Professora titular do Departamento de Educação da Université du Québec à Trois-Rivières

Contato: rollande.deslandes@uqtr.ca

\section{Como citar este artigo:}

SILVA, Nilce; ROUSSEAU, Michel e DESLANDES, Rollande. Participação dos pais e mães na realização da lição de casa no Quebec e no Brasil. Revista ACOALFAplp: Acolhendo a Alfabetização nos Países de Língua portuguesa, São Paulo, ano 4, n. 8, 2010. Disponível em: <http://www.acoalfaplp.net>. Publicado em: março - setembro de 2010

Recèbido em dezembro de 2009./ Aprovado em janeiro de 2010. 